\title{
Effects of tubeimoside-1 on the proliferation and apoptosis of BGC823 gastric cancer cells in vitro
}

\author{
YI ZHANG $^{1}$, XIAO-MAN XU ${ }^{2}$, MENG ZHANG ${ }^{1}$, DAN QU $^{2}$, HUI-YAN NIU ${ }^{1}$, \\ XUE BAI ${ }^{1}$, LIANG KAN ${ }^{1}$ and PING HE ${ }^{1}$ \\ Departments of ${ }^{1}$ Geriatrics and ${ }^{2}$ Respiratory Medicine, Shengjing Hospital of China Medical University, \\ Shenyang, Liaoning 110004, P.R. China
}

Received October 1, 2012; Accepted December 18, 2012

DOI: 10.3892/ol.2013.1117

\begin{abstract}
Natural products isolated from Chinese medicinal herbs are useful sources of new drugs for cancer therapy. Tubeimoside-1 (TBMS1) is a natural compound isolated from the Chinese medicinal herb Bolbostemma paniculatum (Maxim.) Franquet (Cucurbitaceae). Studies have shown that TBMS1 has anticancer effects in various human cancer cell lines. However, the effect of TBMS1 on human gastric cancer cells is unknown. In the present study, it was observed that TBMS1 inhibited BGC823 gastric cancer cell proliferation in a concentration- and time-dependent manner. Fluorescent microscopy and flow cytometric analysis showed that TBMS1 induced BGC823 cell apoptosis in a concentration-dependent manner. Western blot analysis also showed that TBMS1 induced apoptosis by regulation of the Bcl-2 gene family in BGC 823 cells. These findings indicate that TBMS1 may be developed as a possible therapeutic agent for the management of gastric cancer.
\end{abstract}

\section{Introduction}

Gastric cancer is the fourth most common type of cancer and the second most common cause of cancer-related mortality worldwide $(1,2)$. At present, the management of gastric cancer includes surgery, radiotherapy, conventional chemotherapy, molecular targeted therapy and biological therapy. Despite therapeutic advances, the 5-year survival rate of gastric cancer is generally $<20 \%$ (3). Thus, it is necessary to identify more effective therapeutic agents for gastric cancer to improve the survival rate.

A number of studies have drawn attention to natural products extracted from Chinese medicinal herbs as anticancer agents in gastric cancer therapy (4-6). Tubeimoside-1

Correspondence to: Dr Ping He, Department of Geriatrics, Shengjing Hospital of China Medical University, 36 Sanhao Road, Shenyang, Liaoning 110004, P.R. China

E-mail: cmu2h@hotmail.com

Key words: tubeimoside-1, BGC823 gastric cancer cells, natural compound, apoptosis
(TBMS1; Fig. 1) is a natural compound isolated from the Chinese medicinal herb Bolbostemma paniculatum (Maxim.) Franquet (Cucurbitaceae). Previous studies have shown that TBMS1 exhibits a variety of biological activities, including potent anticancer effects in several cancer cell lines, and it has been reported that TBMS1 exerts anticancer effects through the inhibition of cancer cell proliferation and the induction of G2/M phase arrest and apoptosis (7-11). Previously, we reported that TBMS1 inhibits proliferation and induces apoptosis by increasing the Bax to Bcl-2 ratio and decreasing COX-2 expression levels in lung cancer A549 cells (12). However, the effects of TBMS1 on human gastric cancer cells remain unclear.

In the present study, the effects of TBMS1 on the growth of BGC823 gastric cancer cells and the cellular mechanism involved in TBMS1-induced apoptosis were investigated. The findings suggest that TBMS1 may be developed as an anticancer agent for gastric cancer therapy.

\section{Materials and methods}

Reagents and chemicals. TBMS1 was purchased from the National Institute for the Control of Pharmaceutical and Biological Products (Beijing, China) and a $1 \mathrm{mmol} / \mathrm{l}$ stock solution of TBMS1 was dissolved in PBS and stored at $-20^{\circ} \mathrm{C}$. Fetal bovine serum (FBS) was purchased from Solarbio Science and Technology Co., Ltd. (Beijing, China). 3-(4,5-Dimethylthiazol2-yl)-2,5-diphenyltetrazolium bromide (MTT), Hoechst 33342 and dimethyl sulfoxide (DMSO) were purchased from Sigma-Aldrich (St. Louis, MO, USA). The Annexin V-FITC and PI double staining kit were purchased from KeyGene (Nanjing, China). Antibodies were purchased from Santa Cruz Biotechnology Inc. (Santa Cruz, CA, USA). All other reagents were procured locally.

Cell culture. The human gastric cancer cell line BGC823 was obtained from the China Center for Type Culture Collection (Wuhan, China) and maintained in RPMI-1640 supplemented with $10 \% \mathrm{FBS}, 100 \mathrm{U} / \mathrm{ml}$ penicillin and $100 \mu \mathrm{g} / \mathrm{ml}$ streptomycin at $37^{\circ} \mathrm{C}$ in a humidified atmosphere of $5 \% \mathrm{CO}_{2}$.

MTT assay. The effect of TBMS1 on the proliferation of BGC823 cells was measured by MTT assay. Briefly, BGC823 
cells were plated at a density of $1 \times 10^{4}$ cells per well in 96-well plates overnight and then treated with various concentrations of TBMS1 $(0,5,10,15$ and $20 \mu \mathrm{mol} / \mathrm{l})$ for 24 and $48 \mathrm{~h}$. MTT solution ( $20 \mu \mathrm{l}, 2 \mathrm{mg} / \mathrm{ml}$ in PBS) was added to each well and the cells were cultured for a further $4 \mathrm{~h}$ at $37^{\circ} \mathrm{C}$. The medium was then removed and $150 \mu \mathrm{l}$ DMSO was added to solubilize the MTT formazan crystals. Finally, the plates were agitated and the optical density was determined at $570 \mathrm{~nm}$ (OD570) using an ELISA plate reader (Model 550, Bio-Rad, Hercules, CA, USA). At least three independent experiments were performed.

Fluorescence microscopy. BGC823 cells $\left(1 \times 10^{6}\right)$ were seeded in 6-well plates overnight and then treated with different concentrations of TBMS1 ( 0 and $10 \mu \mathrm{mol} / \mathrm{l})$ for $24 \mathrm{~h}$. The cells were washed twice with cold PBS, fixed with cold methanol and acetic acid $(3 / 1, \mathrm{v} / \mathrm{v})$ for $30 \mathrm{~min}$ and then stained with Hoechst $33342(1 \mathrm{mg} / \mathrm{ml})$ for $30 \mathrm{~min}$ in the dark. The stained cells were observed with a fluorescence microscope (x400 magnification, Nikon, Tokyo, Japan).

Flow cytometric analysis. The apoptotic rates of the BGC823 cells were determined by flow cytometric analysis using an Annexin V-FITC Apoptosis kit. Briefly, BGC823 cells (1x106) were seeded in 6-well plates overnight and then treated with various concentrations of TBMS1 $(0,5,10$ and $15 \mu \mathrm{mol} / \mathrm{l})$ for $24 \mathrm{~h}$. Cells $\left(1 \times 10^{6}\right)$ were then harvested by centrifuging $(1,000 \mathrm{rpm})$ and washed twice with cold PBS. The staining was performed according to the instructions of the manufacturer (KeyGene) and then the cells were analyzed using a FACScan flow cytometer (Becton-Dickinson, San Jose, CA, USA). At least three independent experiments were performed.

Western blot analysis. The expression of apoptosis-related proteins was evaluated by western blot analysis. Briefly, BGC823 cells $\left(1 \times 10^{6}\right)$ were seeded in 6-well plates overnight, then treated with various concentrations of TBMS1 $(0,5,10$ and $15 \mu \mathrm{mol} / \mathrm{l}$ ). After treatment for $24 \mathrm{~h}$, the total proteins were solubilized and extracted with lysis buffer $(20 \mathrm{mM}$ HEPES, pH 7.9, 20\% glycerol, $200 \mathrm{mM} \mathrm{KCl,} 0.5 \mathrm{mM}$ EDTA, $0.5 \% \mathrm{NP}-40,0.5 \mathrm{mM}$ DTT and $1 \%$ protease inhibitor cocktail). The protein concentration was determined using a bicinchoninic acid (BCA) protein assay. All samples were separated by SDS-PAGE to determine the expression levels of Bax, Bcl-2 and $\beta$-actin proteins. Blots were developed using an ECL kit.

Statistical analysis. Statistical analyses were performed using the SPSS 13.0 package (SPSS Inc., Chicago, IL, USA). All experiments were conducted at least three times. All data are expressed as the mean $\pm \mathrm{SD}$. The statistical correlations of the data were tested for significance using ANOVA and the Student's t-test. $\mathrm{P}<0.05$ and $\mathrm{P}<0.01$ were considered to indicate statistically significant differences.

\section{Results}

TBMS1 inhibited BGC823 cell proliferation. To investigate the growth inhibiting effects of TBMS1, the BGC823 cells were treated with various concentrations of TBMS1 for 24 and $48 \mathrm{~h}$ and the rate of inhibition was determined by MTT

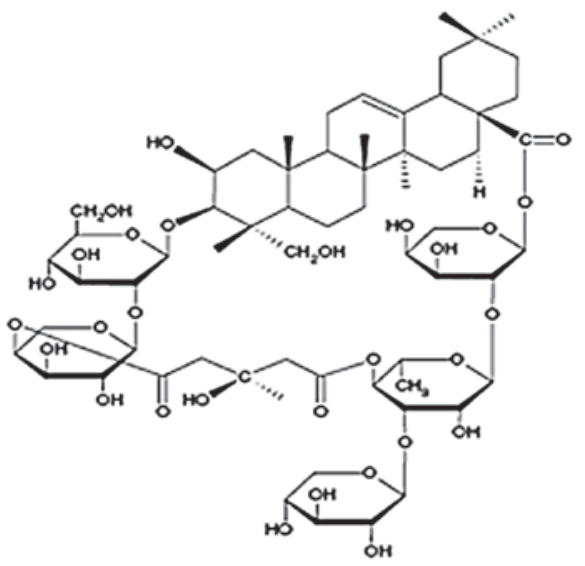

Figure 1. Structure of tubeimoside-1.

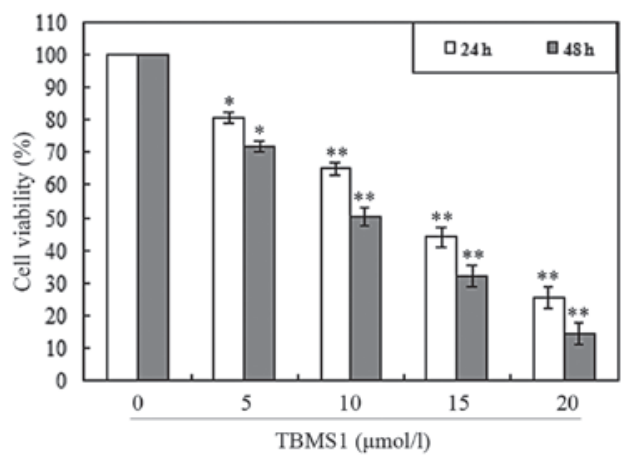

Figure 2. The proliferation inhibiting effects of TBMS1 on BGC823 gastric cancer cells. ${ }^{*} \mathrm{P}<0.05$ vs. the control group. ${ }^{* *} \mathrm{P}<0.01$ vs. the control group. TBMS1, tubeimoside-1.

assays. As shown in Fig. 2, it was observed that the growth of BGC823 cells was inhibited in a concentration- and time-dependent manner.

TBMS1 induced BGC823 cell apoptosis. To investigate the apoptosis-inducing effect of TBMS1, the BGC823 cells were treated with various concentrations of TBMS1. After treatment with TBMS1 ( 0 and $10 \mu \mathrm{mol} / \mathrm{l})$ for $24 \mathrm{~h}$, the cells were examined by fluorescent microscopy using Hoechst 33324 staining. As shown in Fig. 3, chromatin condensation, nuclear fragmentation and apoptotic bodies were observed clearly in the treated cells. The results revealed that when exposed to TBMS1, BGC823 cells underwent the typical morphological changes of apoptosis.

The ratio of apoptotic cells induced by TBMS1 was measured by flow cytometry. BGC 823 cells were treated with various concentrations of TBMS1 $(0,5,10$ and $15 \mu \mathrm{mol} / \mathrm{l})$ for $24 \mathrm{~h}$ and analyzed by flow cytometry using Annexin V and PI staining. As shown in Fig. 4, the ratio of early and late apoptotic cells was significantly increased in the TBMS1-treated cells compared with the control group. The results show that when treated with TBMS1 for $24 \mathrm{~h}$, the ratio of apoptotic cells significantly increased in a concentration-dependent manner.

Effect of TBMS1 on expression levels of the Bcl-2 gene family. The expression of apoptosis-related proteins was evaluated by 


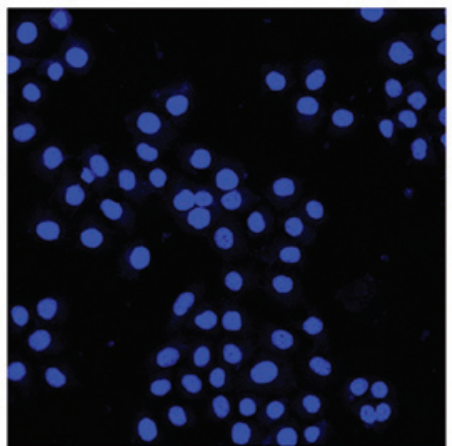

0

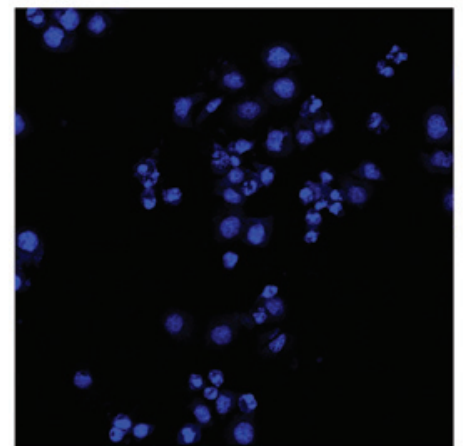

10

TBMS1 $(\mu \mathrm{mol} / 1)$

Figure 3. Cell apoptosis observed by Hoechst 33342 staining. BGC823 cells were treated with TBMS1 (0 or $10 \mu$ mol/l) for 24 h. Apoptotic cells exhibited chromatin condensation, nuclear fragmentation and apoptotic bodies. TBMS1, tubeimoside-1.
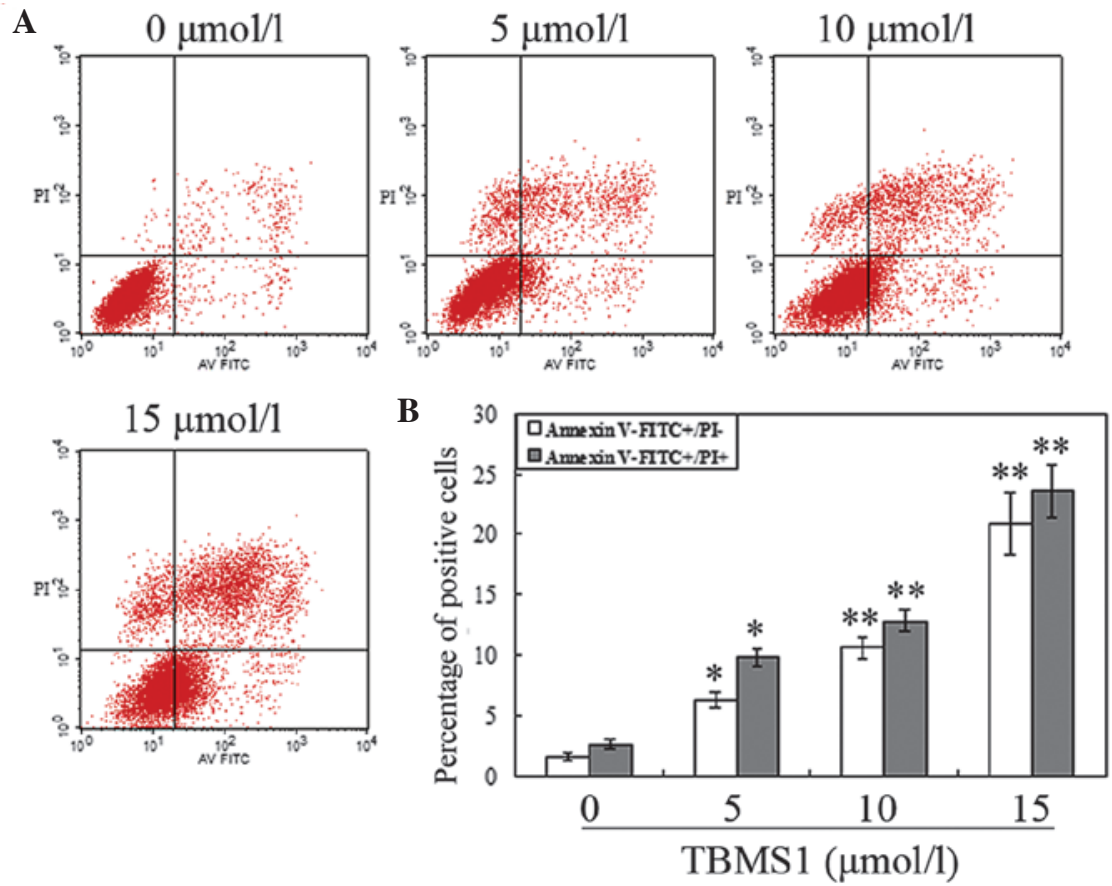

Figure 4. (A) TBMS1-induced apoptosis in BGC823 cells as assayed by flow cytometry. BGC823 cells were treated with TBMS1 $(0,5,10$ and $15 \mu$ mol/1) for $24 \mathrm{~h}$. The cells were then harvested and stained with Annexin V and PI and flow cytometric analysis was performed to analyze the apoptosis. (B) Summary of the apoptosis data in histogram form. ${ }^{*} \mathrm{P}<0.05$ vs. the control group; ${ }^{* *} \mathrm{P}<0.01$ vs. the control group. TBMS1, tubeimoside- 1.

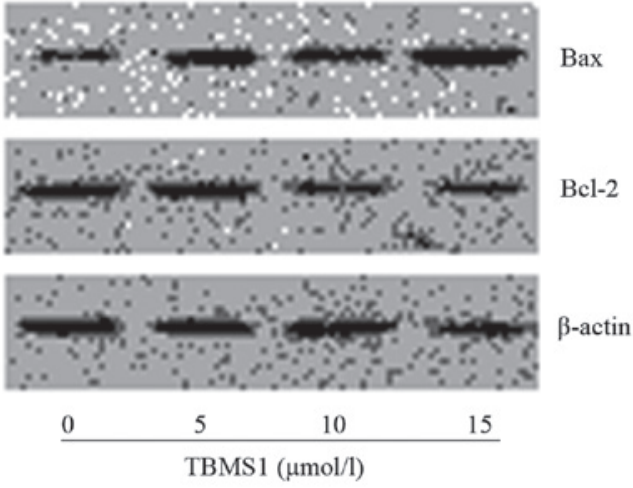

Figure 5. Effect of TBMS1 on Bcl-2 family proteins by western blot analysis. BGC823 cells were treated with TBMS1 $(0,5,10$ and $15 \mu \mathrm{mol} / \mathrm{l})$ for $24 \mathrm{~h}$. Proteins were extracted, then Bax, Bcl-2 and $\beta$-actin expression levels were analyzed by western blotting. TBMS1, tubeimoside-1. western blot analysis. As shown in Fig. 5, TBMS1 treatment led to an increase in Bax levels and a reduction in Bcl-2 levels compared with those in the control cells. The ratio of Bax to Bcl-2 increased in a concentration-dependent manner.

\section{Discussion}

An increasing amount of attention has been focused on the use of natural products isolated from Chinese medicinal herbs for gastric cancer therapy (4-6). TBMS1 is a natural compound extracted from the Chinese medicinal herb Bolbostemma paniculatum (Maxim.) Franquet (Cucurbitaceae), which has been used for a long time in the treatment of numerous diseases and possesses well-documented antiviral, anti-inflammatory and immunosuppressive activities (13-15). The anticancer 
effects of TBMS1 have been documented in numerous types of human cancer (7-12). These studies have revealed that TBMS1 inhibits cell growth and induces $\mathrm{G} 2 / \mathrm{M}$ phase arrest and the apoptosis of cancer cells. However, the effects of TBMS1 on human gastric cancer cells remain unclear.

In the present study, TBMS1 inhibited BGC823 gastric cancer cell proliferation in a concentration- and time-dependent manner. Chromosome condensation, nuclear fragmentation and apoptotic bodies were observed by fluorescent microscopy. Flow cytometric analysis revealed that TBMS1 induced BGC823 cell apoptosis in a concentration-dependent manner. Moreover, the results from the western blot analysis showed that the molecular basis of the TBMS1-induced apoptosis in the BGC 823 cells was via the downregulation of Bcl-2 protein levels and the upregulation of Bax protein expression.

Apoptosis, or programmed cell death, is critical in developmental processes, the maintenance of homeostasis and elimination of damaged cells $(16,17)$. Resistance to apoptosis is a significant hallmark of cancer cells and the induction of apoptosis is one of the major goals of anticancer therapy (18). Several genes are involved in the regulation of apoptosis, such as the Bcl-2 gene family. The Bcl-2 gene family, which is significantly involved in the regulation of cell apoptosis, includes anti-apoptotic genes such as Bcl-2 and Bcl-xl and pro-apoptotic genes including, Bax, Bak, Bik, Bid and $\operatorname{Bad}(19,20)$. The ratio of Bax to Bcl-2 is a decisive factor for the induction of apoptosis and the balance between the expression levels of the proteins Bax and Bcl-2 is critical for cell survival or death. Certain anticancer drugs extracted from Chinese medicinal herbs induce cancer cell apoptosis through the upregulation of the ratio of Bax to Bcl-2 (21-24). Similarly, the present results showed that the expression of Bax was upregulated by TBMS1, whereas that of Bcl-2 was downregulated, leading to an upregulation of the ratio between Bax and $\mathrm{Bcl}-2$. This indicates the involvement of the $\mathrm{Bcl}-2$ gene family in the regulation of TBMS1-induced cell apoptosis.

In conclusion, the present study demonstrated that TBMS1 inhibited proliferation and promoted apoptosis in BGC823 gastric cancer cells. This apoptotic response is associated with the regulation of the expression of the Bcl-2 gene family. The findings indicate that TBMS1 may be developed as a possible therapeutic agent for the management of gastric cancer.

\section{References}

1. Parkin DM, Bray F, Ferlay J and Pisani P: Global cancer statistics, 2002. CA Cancer J Clin 55: 74-108, 2005.

2. Compare D, Rocco A and Nardone G: Risk factors in gastric cancer. Eur Rev Med Pharmacol Sci 14: 302-308, 2010.

3. Jemal A, Siegel R, Ward E, Murray T, Xu J and Thun MJ: Cancer statistics, 2007. CA Cancer J Clin 57: 43-66, 2007.

4. Li N, Fan LL, Sun GP, Wan XA, Wang ZG, Wu Q and Wang H: Paeonol inhibits tumor growth in gastric cancer in vitro and in vivo. World J Gastroenterol 16: 4483-4490, 2010.

5. Chen J, Shi DY, Liu SL and Zhong L: Tanshinone IIA induces growth inhibition and apoptosis in gastric cancer in vitro and in vivo. Oncol Rep 27: 523-528, 2012.
6. Onoda C, Kuribayashi K, Nirasawa S, Tsuji N, Tanaka M, Kobayashi D and Watanabe N: (-)-Epigallocatechin-3-gallate induces apoptosis in gastric cancer cell lines by down-regulating survivin expression. Int J Oncol 38: 1403-1408, 2011.

7. Yin Y, Chen W, Tang C, Ding H, Jang J, Weng M, Cai Y and Zou G: NF- $\kappa B$, JNK and p53 pathways are involved in tubeimoside-1-induced apoptosis in HepG2 cells with oxidative stress and $\mathrm{G}_{2} / \mathrm{M}$ cell cycle arrest. Food Chem Toxicol 49: 3046-3054, 2011.

8. Wang Y, Deng L, Zhong H, Jiang X and Chen J: Natural plant extract tubeimoside I promotes apoptosis-mediated cell death in cultured human hepatoma (HepG2) cells. Biol Pharm Bull 34: 831-838, 2011.

9. Huang P, Yu C, Liu XQ, Ding YB, Wang YX and He JL: Cytotoxicity of tubeimoside I in human choriocarcinoma JEG-3 cells by induction of cytochrome c release and apoptosis via the mitochondrial-related signaling pathway. Int J Mol Med 28: 579-587, 2011.

10. Xu Y, Chiu JF, He QY and Chen F: Tubeimoside-1 exerts cytotoxicity in HeLa cells through mitochondrial dysfunction and endoplasmic reticulum stress pathways. J Proteome Res 8: 1585-1593, 2009.

11. Chen WJ, Yu C, Yang Z, He JL, Yin J, Liu HZ, Liu HT and Wang YX: Tubeimoside-1 induces G2/M phase arrest and apoptosis in SKOV-3 cells through increase of intracellular $\mathrm{Ca}^{2+}$ and caspase-dependent signaling pathways. Int J Oncol 40: 535-543, 2012.

12. Zhang Y, Xu X and He P: Tubeimoside-1 inhibits proliferation and induces apoptosis by increasing the Bax to Bcl-2 ratio and decreasing COX-2 expression in lung cancer A549 cells. Mol Med Rep 4: 25-29, 2011.

13. Yu TX, Ma RD and Yu LJ: Structure-activity relationship of tubeimosides in anti-inflammatory, antitumor, and antitumor-promoting effects. Acta Pharmacol Sin 22: 463-468, 2001.

14. Zhang XH, Sun NX, Guo RX, Xing JL and Liu XN: Efficacy research of tubeimoside against the experimental herpes simplex keratitis. Rec Adv Ophthalmol 22: 373-376, 2002 (In Chinese).

15. Li XH, Wang P, Fu ZC, et al: Effects of Bolbastemmosaponins A on immunologic functions of experimental animals. China Pharm 9: 13, 1998 (In Chinese).

16. Yagi Y, Fushida S, Harada S, Kinoshita J, Makino I, Oyama K, Tajima H, Fujita H, Takamura H, Ninomiya I, Fujimura T, Ohta T, Yashiro M and Hirakawa K: Effects of valproic acid on the cell cycle and apoptosis through acetylation of histone and tubulin in a scirrhous gastric cancer cell line. J Exp Clin Cancer Res 29: $149,2010$.

17. Xiao R, Ferry AL and Dupont-Versteegden EE: Cell death-resistance of differentiated myotubes is associated with enhanced anti-apoptotic mechanisms compared to myoblasts. Apoptosis 16: 221-234, 2011.

18. Hanahan D and Weinberg RA: Hallmarks of cancer: the next generation. Cell 144: 646-674, 2011.

19. Robertson JD and Orrenius S: Molecular mechanisms of apoptosis induced by cytotoxic chemicals. Crit Rev Toxicol 30: 609-627, 2000

20. Tamm I, Schriever F and Dörken B: Apoptosis: implications of basic research for clinical oncology. Lancet Oncol 2: 33-42, 2001.

21. Yu J, Zhou X, He X, Dai M and Zhang Q: Curcumin induces apoptosis involving bax/bcl-2 in human hepatoma SMMC-7721 cells. Asian Pac J Cancer Prev 12: 1925-1929, 2011.

22. Xu YH, Zhao LJ and Li Y: Alisol B acetate induces apoptosis of SGC7901 cells via mitochondrial and phosphatidylinositol 3-kinases/Akt signaling pathways. World J Gastroenterol 15: 2870-2877, 2009.

23. Jiang T, Zhou L, Zhang W, Qu D, Xu X, Yang Y and Li S: Effects of sinomenine on proliferation and apoptosis in human lung cancer cell line NCI-H460 in vitro. Mol Med Rep 3: 51-56, 2010.

24. Xu X, Zhang Y, Qu D, Jiang T and Li S: Osthole induces G2/M arrest and apoptosis in lung cancer A549 cells by modulating PI3K/Akt pathway. J Exp Clin Cancer Res 30: 33, 2011. 